variety just because sociobiology can explain so much of our behavioural history. I found this section, and the twochapter, fifth and final section on creationism, unprepossessing.

The guts of the book lie, appropriately enough, in its middle, in parts two and three. Here Ruse tells us what evolutionary biology really is, and should be, all about. I find it a dismal picture. The approach Ruse advocates is pure storytelling - or, as he himself puts it, continued indulgence in evolutionary biology's "favorite parlor game": concocting plausible scenarios of how the elephant got its trunk, the rhino its wrinkled skin and the giraffe its long neck. To Ruse, we know the mechanism, and it's all just a bunch of clever games applying this mechanism of genetic change to explain literally all manner of evolutionary phenomena.

Most critics of contemporary evolutionary theory, myself included, would agree that natural selection is a deterministic mechanism accounting for generation-by-generation change in gene frequencies within populations. It is even testable, given the appropriate data which involve gene frequencies and generations. But reducing, say, ammonite evolution to a just-so story with natural selection as the hero is, as Ruse says, nothing but a parlour game. The difference between us is that Ruse thinks this state of affairs is just fine. I think parlour games are fine too - but I still cherish the fantasy that $1 \mathrm{am}$ doing, or at least am trying to do, science when I'm practising my profession.

Ruse uses analogy and circumstantial evidence as his cornerstone criteria for establishing the validity of scientific ideas. Claiming Darwin used Herschel and Whewell as models, and that analogy and inference were what made science "good" in the $1850 \mathrm{~s}$, Ruse (as he does so much throughout the book) in effect argues that what was good enough for Darwin should suffice for us as well. There is little here of the spirit of enquiry. We are not enjoined, for example, to hold our notions lightly, to walk humbly before Mother Nature, ready to modify our schemes should the evidence of our senses not rhyme with our fondest notions.

Nowhere in this single-minded tract is Ruse's dedication to the almighty principle of natural selection better displayed than in his little section on trilobite vision. The mathematically "perfect", shape of phacopid and dalmanitid lenses is, to Ruse, exquisite evidence of the power of natural selection. I confess I cannot fathom the difference between Ruse's argument and the older creationist argument from design: see this organ system; observe its intricacy! Only (God, natural selection) could have fashioned such a marvellous organic machine! There is a difference, of course: God, as a supernatural being, does not belong in science, whereas natural selection patently does. But used in this inappropriate fashion, natural selection becomes a mere substitute for the Creator. It tells us nothing, really, about trilobite eyes or anything specific or meaningful about how they came into existence.

In short, Ruse is a reductionist - all large-scale evolutionary phenomena are readily explicable in terms of population genetics. But there is more than mere reductionism here: he also dismisses molecular biology, simply because population genetics revealed the contents of Darwin's "black box" of heredity, and molecular biology, Ruse avers, has not changed that one whit. All remains secure. That there are patterns of organization with historical implications emerging from molecular and developmental biology that seem to require their own mechanisms in addition to those of population genetics is missing in Ruse's world view. Indeed, in his reflexively negative reaction to the winds of change, Ruse fails to see that the newer arguments are nearly all additive: natural selection explains changes in gene content and frequency within populations, but more than populations are involved in evolution. Another example: Ruse doesn't even bother to mention the idea that species are individuals - the ontological claim underlying the view that macroevolution may be something more than just scaled-up microevolution.

Darwin and his ideas need no defence. I agree with Ruse: Darwin was a good scientist. In that spirit I would rather imagine Darwin enjoying the spectacle of biologists vigorously debating his, and descendant, notions over a century after the Origin. Ruse, appropriating Darwin's shade as his alone, seems to think that to question some of Darwin's notions is somehow to impugn the man. So he springs to the defence. It is a clumsy defence, one that certainly does Darwin no credit. As a statement of the nature and effective extent of neo-Darwinism, it is nowhere as good as, say, the September 1978 issue of Scientific American, or any of a number of recent texts. As a book aimed at a general audience, it projects a jolly Alice in Wonderland sort of picture that, I fear, will not do overly much for our collective image in the long run. Darwinism, indeed, the entire field of contemporary evolutionary biology, deserves far better.

Niles Eldredge is at the American Museum of Natural History, New York. His most recent book, The Monkey Business: A Scientist Looks at Creationism, will shortly be published by Washington Square Press.

\title{
A new paradigm for evolutionary change?
}

\section{R.D. Martin}

The New Evolutionary Timetable: Fossils, Genes and the Origin of Species. By S.M. Stanley. Pp.222. US ISBN 0-465-05013-1; UK ISBN 0-633-7022-8. (Basic Books/ Harper \& Row: 1982.) \$16.75, £9.50.

IT IS, perhaps, appropriate that the centenary of Charles Darwin's death should be approximately marked by renewed controversy over the process of evolutionary change. The latest debate concerns one of the most fundamental features of Darwin's theory of evolution by natural selection - gradual change within individual species populations over time. An alternative interpretation, stated with particular clarity by Eldredge and Gould in a seminal paper published in $1972^{1}$, is that most evolutionary change occurs when a new species develops (during a "speciation event") and that there is little change subsequent to establishment of a species.

In some circles, at least, replacement of the Darwinian concept of "gradualism" by the new model of evolution by "punctuation" has been hailed as a fully-fledged scientific revolution (a Kuhnian paradigm change). To date, however, the debate has raged largely among academics, and for this reason Steven Stanley's The New Evolutionary Timetable is both timely and

${ }^{1}$ Eldredge, N. \& Gould, S.J. in Models in Paleobiology (ed Schopf, T.J.M.), 82-115 (Freeman \& Cooper, 1972). welcome. Following hard on the heels of his influential scientific text Macroevolution: Pattern and Process (W.H. Freeman, 1979) this new book attempts to present the case in terms understandable to the non-specialist. Stanley achieves his aim with considerable success, carrying the reader along with a style that is at once lively and informative. Penetrating insights abound as the arguments are presented, and frequent touches of wry humour add a special touch. (Any modern biologist struggling for a command of the literature will surely be relieved to learn that Darwin actually possessed an uncut copy of Mendel's monograph on hereditary mechanisms!) Certainly, a reading of this book leaves one with plenty of food for thought, regardless of the correctness of Stanley's own conclusions. This is a particularly productive time for the remodelling of evolutionary theory, and The New Evolutionary Timetable conveys the excitement felt by many biologists involved.

Underlying the concept of punctuated evolution is an undeniable fact derived from recent palaeontological studies: numerous fossil species have been found which exhibit a remarkable degree of stability ("morphological stasis") over long periods of geological time. It must at once be added that such statis can only be recorded for certain body parts (molar teeth of mammals or shells of molluscs, for 
example) and it is reductionist to conclude that entire organisms remain unchanged over time. Differential evolution of individual body components (mosaic evolution) is a widely recognized phenomenon and there is, for instance, no indication of stasis at the level of the structural gene. Stanley makes little mention of the substantial literature on molecular evolution, which suggests a hiatus between rates of evolution of single proteins and those of whole organisms. It is all too easy to slip into equating fossilized skeletal parts with entire organisms, and this slip is a recurrent feature of the literature of punctuated evolution. Stanley, for example, asserts that Homo sapiens has undergone almost no bodily change since appearing in Europe some 40,000 years ago.

The second aspect of the punctuational model is rapid evolution during speciation, which is generally assumed to occur in relatively or very small, peripheral populations. Such rapid evolution must, however, be inferred from the fossil record and involves the assumption that the fossil record is sufficiently complete to document this process unequivocally. In a few special cases this may be true, but the fossil record as a whole is pitifully inadequate - there is, for example, only one major fossil site recording the occurrence of mammals in the entire African continent for the first 35 million years of the Tertiary. We really

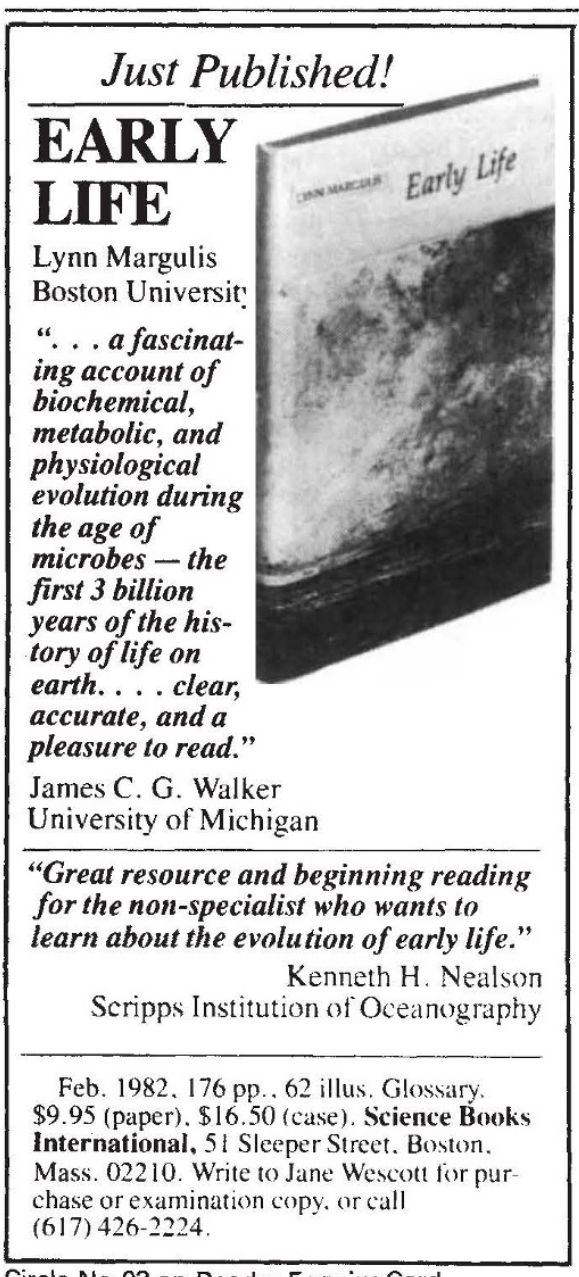

Circle No.03 on Reader Enquiry Card. need to have estimates of the relationship between the likely catchment areas of relevant fossil sites and the geographical ranges of equivalent modern species; in the absence of such estimates a reasonable guess is that fossil sampling is in fact extremely patchy.

Nevertheless, the picture now emerging from the fossil record is unsettling, and our ideas of evolutionary processes must undoubtedly progress to account for longterm stasis, at least in individual body parts, in species populations. The question is whether such progress requires no more than healthy readjustment of basic theory or whether the changes which occur during speciation dictate recognition of a radically new process ("quantum speciation" or "macroevolution"). Stanley is convinced that the Iatter is the case. Perhaps understandably, he does not fix upon a single basic mechanism of "macroevolution", though he does somewhat vaguely implicate chromosomal reshuffling. Everything really hangs on the rapidity with which speciation takes place. Stanley states that he is prepared to envisage thousands of generations as the time-scale for "quantum speciation", and this could well be accommodated within a traditional model of evolutionary change. Stanley feels that the fossil evidence for human evolution provides us with one of the best illustrations of punctuation, yet "thousands of generations" could occupy a considerable proportion of the average geological duration of the hominid species currently recognized. In any case, the situation is far more complex than Stanley suggests, notably in the existence of intermediate forms (see Cronin et al., Nature 292, 113-122). Stanley himself is somewhat unclear about the actual limits of his model as well. He suggests (p.157) that human races ("subspecies") may have arisen by punctuated evolution. Quite apart from the fact that here he is treading on extremely contentious ground in sociopolitical terms, it is difficult to see what "quantum" differences might define the human races in any context relevant to punctuated evolution.

In the absence of a clear model of the mechanism of "quantum speciation", the case for a radically new paradigm remains somewhat unconvincing, as was the case with continental drift prior to the recognition of sea-floor spreading. Stanley devotes a whole chapter to demonstrating that his doubts about conventional theory do not open the door to creationism; but without a clear concept of the mechanism involved in "punctuated evolution" he is unlikely to convince any creationist? Stanley is right to alert the general reader to the surprising new findings of palaeontologists, but he really goes much farther than the present evidence permits.

R.D. Martin is Reader in Physical Anthropology at University College London and Visiting Professor in Zoology at Birkbeck College, University of London.

\section{Two sides of Darwin}

\section{A.J. Cain}

Darwin. By Jonathan Howard. Pp.101. Hbk ISBN 0-19-287557-4; pbk ISBN 0-19-287556-6. (Oxford University Press: 1982.) Hbk £5.50; pbk £1.25. To be published in the USA later this year. Darwin. By Wilma George. Pp.160. ISBN 0-00-636502-7. (Fontana: 1982.) £1.75.

IT Is a sign of Darwin's relevance that Jonathan Howard's book is in the OUP Past Masters series, Wilma George's in the Fontana Modern Masters. They are nearly identical in their rather nasty format (dirtycoloured paper, undistinguished type-face and over-gorgeous covers, rather like the trash-novels on a railway bookstall), but do not be put off by first appearances - their intellectual content is very good, and both are well worth the money. Both are written by practising zoologists - a refreshing change from so many books on Darwin but zoologists of very different interests. Jonathan Howard is a Principal Scientific Officer at the ARC Institute of Animal Physiology at Babraham, Wilma George is a University Lecturer in the Department of Zoology, Oxford. There is also a useful difference of sex; some of Wilma George's comments on the acceptability of Darwin's theories of sexual selection and male aggression to Victorian men are particularly enlightening.

Jonathan Howard remarks in his preface that

With the centenary of Darwin's death comes a widespread mood of scepticism and unease about the validity and significance of Darwin's contribution to knowledge. The time is certainly right to try to describe Darwin's scientific work briefly and in plain language.

While fully recognizing the importance of Darwin's work for biology, he says "I hope the book is fair in pointing out aspects of Darwin's thinking which lack consistency or have failed to stand up to critical scrutiny". And he rightly emphasizes that whatever others have made of Darwinism in philosophy or sociology, and however true it is that "human life and human society are to a certain extent biological issues", it is Darwin's contribution to biology on which he must stand or fall. "Darwinian philosophy of Darwinian society are post-hoc constructs that had no place in Darwin's thought".

The chapters take us successively through Darwin's life; the foundations of Darwinism; natural selection and the origin of species; the evidence for evolution by natural selection; sex, variation and heredity; man; perfection and progress; Darwinism and ideology; and Darwin as a scientist - an evaluation. The style is mostly good and the exposition clear. Just occasionally it would have benefited from critical reading - for example I can make no sense out of Howard's comment on 